\title{
Asthma Guidelines Supplement
}

\section{Edited by: Dr John Haughney and Dr Mark Levy}

Authors:

Dr John Haughney

Address for correspondence

General Practitioner, Glasgow

Chairman, GPIAG

Alison Lea Medical Centre

Member of Steering Group, British Asthma

Calderwood

Guidelines

East Kilbride G74 3BE

Telephone: + 44 (0)1355 261666

Email: j.haughney@abdn.ac.uk

Dr Rupert Jones

General Practitioner, Devon

Research Unit Director, University of Plymouth

Member of GPIAG Research committee
Respiratory Research Unit, Dept. of Primary

Health Care and General Practice

University of Plymouth

ITTC Building, Tamar Science Park

Plymouth, Devon

Email: rupertjones@ukgateway.net

Dr Mark Levy

Editor, General Practice Airways Group GPIAG Senior Lecturer, University of Aberdeen Member of the Acute Asthma Working Group of the British Guidelines

\section{Kenton Bridge Medical Centre}

155-175 Kenton Road

Kenton

Harrow HA3 0YX

Telephone: +44 (0)208907 6989

Email: marklevy@animalswild.com

\section{Ms Philippa Madge}

\section{NAC/NRTC}

Senior Research Fellow in Delivery of Care
Department of Child Health,

Yorkhill NHS Trust, Glasgow

Scotland, G3 8SJ

Telephone: +44 (0)141 2010670

Email: p.madge@clinmed.gla.ac.uk

\section{Dr Hilary Pinnock}

\section{GPIAG Clinical Research Fellow,}

University of Aberdeen

Principal in General Practice, Kent
Whitstable Health Centre

Harbour Street, Whitstable

Kent CT5 1BZ

Tel: +44 (0)1227 594400

Email: hpinnock@gpiag-asthma.org

Dr Mike Thomas

Principle in General Practice, Gloucs

GPIAG Research Fellow, University of Aberdeen

Primary Care Adviser, Gloucester Research \&

Development Support Unit

Hospital Practitioner Respiratory Medicine, Stroud Hospital
The Surgery

Minchinhampton, Stroud

Gloucester GL6 9JF

Telephone: +44 (0)1453 883793

Email: drmthomas@oakridge.sol.co.uk 


\section{Section 1 Introduction}

$\mathrm{I}$ this supplement to the Primary Care

Respiratory Journal (PCRJ), we present useful

practical advice relevant to primary care, summarised from the new BTS/SIGN British

Guideline on the management of asthma, with additional supporting practical advice. This supplement is intended for use in conjunction with the guidelines, and not as a replacement.

The main aims of this publication are:

- to support the implementation of the guidelines in general practice

- to raise standards of asthma care

- to promote debate, education and further thinking

This supplement has been co-authored by active primary care clinicians who have been involved in the production of the guidelines and is aimed at primary care clinical colleagues.

\section{Background}

The appearance of the long-awaited new BTS/SIGN British Guideline on the management of asthma is welcome and much needed by those working in primary care.

The guidelines have been produced according to the system developed by the Scottish Intercollegiate Network (SIGN) in collaboration with various organisations including the British Thoracic Society and the General Practice Airways Group (GPIAG).

The great majority of people with asthma are managed by primary care health workers in the community.

The previous British guidelines are outdated. The new guidelines are extensive in scope, and are an important and valuable reference resource. The quick reference guide of summaries will be of great practical assistance to clinicians.

The guideline development process involved a review of more than 16,000 clinical papers culled from an extensive literature search. These were appraised by nine multi-disciplinary review groups, who systematically reviewed and summarised the papers in the form of evidence tables from which they produced graded recommendations. The process is summarised in Figure 1.1 and the grading systems in Tables 1.1 and 1.2. The evidence tables for the papers reviewed are available on the SIGN website at www.sign.ac.uk

All the guidelines' recommendations are graded on a scale from A (based on high-grade evidence) to D (based on expert opinion). This allows us to see the strength of evidence behind recommendations, and reveals areas where the current evidence is scanty and further research is needed.

It is important to note that the grading system refers to the strength of evidence relating to it and not its clinical importance. The absence of evidence does not imply a lack of clinical importance.

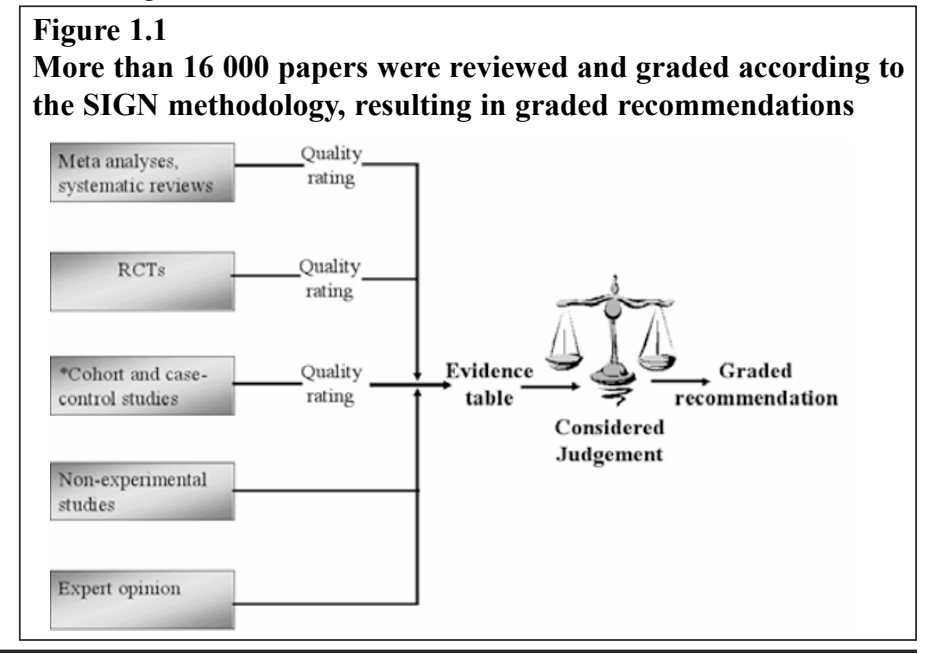




\section{Table 1.1 SIGN evidence grading table}

\section{Levels of evidence}

$1^{++}$High quality meta-analyses, systematic reviews of randomised controlled trials (RCTs), or RCTs with a very low risk of bias

$1^{+} \quad$ Well-conducted meta-analyses, systematic reviews, or RCTs with a low risk of bias

$1^{-} \quad$ Meta-analyses, systematic reviews, or RCTs with a high risk of bias

$2^{++}$High quality systematic reviews of case control or cohort studies

High quality case control or cohort studies with a very low risk of confounding or bias and a high probability that the relationship is causal

$2^{+} \quad$ Well-conducted case control or cohort studies with a low risk of confounding or bias and a moderate probability that the relationship is causal

$2^{-} \quad$ Case control or cohort studies with a high risk of confounding or bias and a significant risk that the relationship is not causal

$3 \quad$ Non-analytic studies, e.g. case reports, case series

$4 \quad$ Expert opinion

\section{Table 1.2 SIGN grades of recommendation}

A At least one meta-analysis, systematic review, or RCT rated as $1^{++}$, and directly applicable to the target population; or

A body of evidence consisting principally of studies rated as $1^{+}$, directly applicable to the target population, and demonstrating overall consistency of results

B A body of evidence including studies rated as $2^{++}$, directly applicable to the target population, and demonstrating overall consistency of results; or

Extrapolated evidence from studies rated as $1^{++}$or $1^{+}$

C A body of evidence including studies rated as $2^{+}$, directly applicable to the target population and demonstrating overall consistency of results; or

Extrapolated evidence from studies rated as $2^{++}$

D Evidence level 3 or 4; or

Extrapolated evidence from studies rated as $2^{+}$

\section{Good practice points}

$\checkmark \quad$ Recommended best practice based on the clinical experience of the guideline development group 


\section{About this supplement}

$\mathrm{T}$

his supplement highlights key areas of the new BTS/SIGN British Guideline on the management of asthma (referred to as the guidelines in this document) relevant to busy health professionals working in primary care.

Each section starts with a list of key messages. We have reproduced a number of tables from the guidelines, with permission.

The supplement is not intended to replace the guidelines, and we recommend reading the full document and using the annexed charts.

Here is an overview of the rest of the supplement:

\section{Section 2}

The diagnosis of asthma

Emphasis is placed on accuracy of diagnosis with recommendations for use of objective tests where possible before long-term therapy is started. In particular the diagnosis should be reconsidered in patients who fail to respond to asthma therapy.

\section{Section 3}

Pharmacological management - chronic asthma

The importance of inhaled steroids is stressed. However, the use of high doses of steroids should be carefully monitored. Therapeutic trials, observation of results and trial of alternative options (and discontinuation of ineffective ones) are needed.

\section{Section 4 \\ Education, self-management and compliance}

These form a complete package that underpins all aspects of asthma care. This section provides background information and practical suggestions.

\section{Section 5}

Uncontrolled asthma in general practice

The section provides suggestions for improved management of acute asthma. Difficulties of diagnosis, recommended immediate treatment and the need for review after 48 hours are discussed.

\section{Section 6}

Special situations - pregnancy, infants and occupational asthma

Each category requires a systematic approach. Referral to secondary care specialists is recommended if primary care health workers are concerned about a patient in any of these categories.

\section{Section 7}

Organisation of care and audit

This section deals with maintaining a structured system for managing asthma in the practice, including systems for identifying and recalling patients at risk, for recording clinical data and arranging follow up within 48 hours of acute asthma treatment. Practical suggestions and tables are included. 


\section{Section 2 \\ The diagnosis of asthma}

\section{Key messages}

- Objective tests should be used where possible to confirm a diagnosis of asthma before long-term therapy is started

- Clinicians should record the criteria used to make the diagnosis

- Failure to respond to asthma therapy should prompt further consideration

$\mathrm{M}$ aking a diagnosis of asthma in primary care may be, but is not always,

straightforward. Clinicians are hampered by the lack of a clear, agreed definition of asthma. In some situations, e.g.. clinical trials, conforming to a "precise" definition is required.

Often in primary care it is reasonable to make a diagnosis of asthma in a patient with symptoms and/or signs of asthma if the history and background are consistent with asthma, other conditions have been excluded, and the patient responds to asthma therapy. However, whenever possible, objective tests should be used to confirm the diagnosis before long-term therapy is started.

People with asthma may suffer from a variety of symptoms, which may not all be present simultaneously and none of which are specific for the condition. These are:

- Wheeze

- Shortness of breath

- Chest tightness

- Cough

These symptoms are usually variable, intermittent, worse at night and provoked by triggers.

Often, on examination of patients with asthma there are no signs, even in the presence of severe uncontrolled asthma. The presence of wheeze is the cardinal sign of asthma, and it is worth recording in the clinical notes.
A personal or family history of asthma, rhinitis or eczema, or a worsening of symptoms after exposure to a "trigger" will contribute to making the diagnosis.

\section{Peak expiratory flow (PEF)}

The standard objective test for asthma used in primary care is PEF. Clinicians are familiar with the concept of PEF variability, i.e.. the tendency for a patient's peak flow to vary over time. The BTS/SIGN British Guideline on the management of asthma ${ }^{1}$ recommend twice daily PEF monitoring for a period of two weeks. Variability is calculated as (highest PEF-lowest PEF)/highest PEF x 100.

\section{Table 2.1. PEF variability: an example}

Highest peak flow $=400 \mathrm{l} / \mathrm{min}$

Lowest peak flow $=300 \mathrm{l} / \mathrm{min}$

Variability: $(400-300) / 400 \times 100=25 \%$

Ideally, variability would be seen over several days during the monitoring period. A variability of $20 \%$ or more (minimum $60 \mathrm{l} / \mathrm{min}$ ) is highly suggestive of asthma. Smaller changes, or little change, do not, of course, rule out the diagnosis.

A single peak flow carried out in the surgery is not helpful in making a diagnosis of asthma, but may help in monitoring asthma control over time. Reversibility tests can, however, be carried out in the surgery (see below). For long term monitoring, the patient's Best Ever PEF is accepted as the reference value for comparing readings from time to time. The Best Ever PEF can be determined when patients are well.

\section{Reversibility tests in the surgery}

Patients with suspected asthma presenting in surgery with low PEF readings may be diagnosed by measuring their PEF before and 10 minutes after administering a $\$ 2$-agonist bronchodilator 
(e.g. salbutamol, terbutaline) by any device, or nebuliser. An increase of $20 \%$ or more is suggestive of asthma.

Spirometry is increasingly available in primary care and the reversibility test can be carried out, perhaps more accurately, using forced expiratory volume in the first second $\left(\mathrm{FEV}_{1}\right.$; ; a change in $\mathrm{FEV}_{1}$ of $15 \%$ is considered suggestive of asthma.

If a patient, particularly a child, presents with possible asthma, you can carry out an exercise test. Take a PEF reading, then ask the patient to exercise for six minutes, e.g. run round the block. On the patient's return, check the peak flow again. A drop of $20 \%$ or more is suggestive of asthma. In these cases, it is important to have adequate emergency treatment available.

Regardless of the circumstances, clinicians should record the criteria used to make the diagnosis.

\section{When to refer}

Asthma can usually be diagnosed and managed in primary care. Indications for referral include:

- Persistent shortness of breath

- Fixed or unilateral wheeze

- Persistent chest pain

- Weight loss

- Persistent or productive cough

- Lung function tests which don't fit with the clinical picture

- Unexpected clinical findings

- Parental or clinician concern

\section{Differential diagnosis}

Many other conditions - chronic obstructive pulmonary disease (COPD), lung and other tumours, cardiac disease, bronchiectasis, hyperventilation, vocal cord dysfunction - share symptoms and signs with asthma. A chest $\mathrm{X}$-ray is often helpful in these cases.

Remember that conditions can coexist, and it is possible to be, for example, an elderly heavy smoker with asthma. In these older adults, differentiating COPD from asthma is a common clinical task. COPD should be considered in patients with cough, sputum production and dyspnoea and/or a history of risk factors for the disease. In the UK, the most common risk factor by far is cigarette smoking. Unlike asthma, it is characterised by airflow limitation that is not fully reversible.

A careful history and examination, supported by spirometry tests, can often help in differentiating COPD from asthma. This has important implications for further management: therapeutic and non-therapeutic interventions for the two conditions are quite different.

\section{Children}

The diagnosis of asthma can be particularly difficult to make in young children. It is frequently not possible to measure lung function, the history and symptoms are often non-specific, and clinical signs are often absent on examination. These children should be placed in one of three categories:

- Normal child (this is not as easy as it might look)

- Serious illness, e.g. cystic fibrosis or TB (rare but important)

- A child with asthma

Alternative diagnoses must always be considered - recurrent upper respiratory tract infections (perhaps with viral associated wheeze), cystic fibrosis (symptoms from birth, failure to thrive), reflux disease (poor feeding, posseting or vomiting), inhaled foreign body (from the history and not variable symptoms or signs). Wheeze is the cardinal sign of asthma, and asthma should be suspected in any child with wheezing heard by a clinician on auscultation.

A wait-and-see approach is often necessary. Clinicians should not succumb to pressure and rush to a diagnosis. Repeated reassessment of the clinical condition is valuable. Trials of therapy - questioning the diagnosis if the management is unsuccessful - are likely to lead to a more accurate diagnosis, which may have important long-term consequences.

Asthma usually can and should be managed in the 
community, but referral for specialist investigation or support is sometimes required (see Table 2.2).

Table 2.2 Indications for referral of children with suspected asthma for specialist opinion/further investigation

- Diagnosis unclear or in doubt

- Excessive vomiting or posseting

- Symptoms present from birth or perinatal lung problem

- Severe upper respiratory tract infection

- Persistent wet cough

- Family history of unusual chest disease

- Failure to thrive

- Unexpected clinical findings e.g. focal signs in the chest, abnormal voice or cry, dysphagia, inspiratory stridor

- Failure to respond to conventional treatment (particularly inhaled corticosteroids above $400 \mathrm{mcg} /$ day or frequent use of steroid tablets)

- Parental anxiety or need for reassurance

\section{Prognosis of childhood asthma}

The implications of making a diagnosis of asthma can be considerable for the child with asthma and his/her carers, as well as in terms of potentially long-term therapeutic decisions. A number of longitudinal studies have reported risk factors for the expression and persistence of asthma. These include:

- A family history of atopy, particularly on the mother's side, is a significant risk factor for late onset childhood asthma

- Boys appear to have an increased risk of asthma up to puberty, while girls with asthma are more likely to continue to suffer the condition in adulthood

- The co-existence of atopic disease, bronchiolitis in infancy, parental (particularly maternal) smoking, low birth weight and premature birth, all appear to increase the likelihood of developing wheezing in childhood, but the association weakens as the child grows into adulthood.

Case finding
It is important to create and maintain an accurate asthma register in a practice and it can be helpful to categorise registers using consistent agreed computer codes in order to assist with long-term management and audit, for example:

- Active asthma: patients who are currently (i.e. in the past two years) receiving asthma therapy and require observation and review

- Possible asthma: often, but not always, children who have not yet been diagnosed, a "wait and see" scenario

- Inactive asthma, or asthma in remission: patients who have been diagnosed, but who have not received therapy, nor attended with an asthma-related consultation in the last two years. These patients are often excluded from call-up for review or from audit

- Patients with COPD: they will have alternative management plans and possibly different review procedures

Case finding may include Read code searching, or a computer search of patients who have ever been prescribed medication for respiratory symptoms (including those used for asthma, allergic rhinitis or COPD) and those with entries related to respiratory diagnoses and out-of-hours events; with a further manual inspection of the clinical notes. This is necessary to confirm a diagnosis of asthma or COPD.

Patients' records should then reflect the diagnostic criteria used. Anecdotal evidence suggests a lack of detailed recorded evidence in GP records for diagnosis of asthma or COPD.

The implications of diagnosing asthma can be far reaching, and making the diagnosis correctly is the cornerstone of achieving success in further management. 


\section{Section 3, Pharmacological management - chronic asthma in adults and children}

\section{Key messages}

- Outcomes of asthma care remain sub-optimal in the UK, and the BTS/SIGN British Guidelines on the management of asthma ${ }^{1}$ provide encouragement and assistance in improving the way we treat our patients

- Asthma is a variable disease and not all patients will respond in the same way. Therefore therapeutic trials, observation of results and trial of alternative options (and discontinuation of ineffective ones) are needed

- GPs and practice nurses, the front-line asthma care providers in the community, need to be aware of patients' agendas, their hopes and fears about their asthma and its treatment, and be prepared to be flexible and to respond appropriately

- The guidelines provide an opportunity to review the management of patients with asthma in primary care, which should help to improve outcomes

- The importance of inhaled steroids is emphasised. However the use of high doses of steroids may not be the best option in many situations, and should be carefully monitored, particularly in children. Doses of greater than $400 \mathrm{mcg} /$ day should not be used in children under 5 without specialist assessment and without a trial of a leukotriene receptor antagonist (LTRA).

\section{Introduction}

The new guidelines cover many important aspects of the management of asthma that are of interest and relevance to GPs and nurses working in the community.

It is fair to assume that many clinicians will turn to the

chapter on pharmacological management first, and likely that the summary diagrams based on this section will be pinned on the surgery wall.

This section summarises the messages described in the pharmacological management chapter, concentrating on the changes from the previous British guidelines.

The basic stepwise management structure is familiar, but a number of important key messages emerge from the comprehensive evidence-based literature review.
Aims of management

The aims of pharmacological management are described in the guidelines as:

- the control of symptoms, including nocturnal and exercise-induced symptoms

- prevention of exacerbations

- achievement of best possible lung function with minimal side effects (see Table 3.1)

It is recognised however that patients' agendas are sometimes different from those of medical professionals, and that they may wish to balance these aims against personal factors, such as worry about sideeffects or the inconvenience of taking medication. It is important that patients' perspectives are taken into account by involving them in pharmacological decision-making. Asthma control should be assessed by the following standards:

- Day and night symptoms

- Reliever medication use

- Exacerbations

- Physical activity limitation

- Lung function $\left(\mathrm{FEV}_{1}\right.$ and/or $\mathrm{PEF}>80 \%$ predicted)

Table 3.1:

Aims of pharmacological management

- Control of daytime symptoms

- Control of nocturnal symptoms

- Control of exercise-induced symptoms

- Prevention of exacerbations

- Achievement of best possible pulmonary function

- Minimal side-effects 
These standards provide potential measures for assessing the appropriateness and success of our pharmacological management.

Over-use of reliever medication (more than 10 to 12 puffs per day, or more than two canisters of short-acting B2-agonist bronchodilator/month) is a marker of poorly controlled asthma. Use of more than one canister of $\beta 2$-agonist bronchodilator a month should prompt clinical review.

More than one puff per day of a $\beta 2$-agonist bronchodilator may indicate a need for a step up in regular therapy.

Many general practices use computerised repeat prescribing. Therefore these markers of poor control may enable us to target patients at risk of exacerbations.

The guidelines give useful advice on when and how to start pharmacological treatment (see Table 3.2), and also on therapy options at step 3 and above (see Table 3.3).

\section{Short-acting bronchodilators}

Inhaled short-acting B2-agonist bronchodilators are the short-term reliever treatment of choice and
Table 3.3: Step 3 and above

- Most patients will be controlled at step 2 standard doses of inhaled steroids (adults $400-800 \mathrm{mcg}$, children $<12$ years, 200 $400 \mathrm{mcg}$ beclomethasone or equivalent)

- If not controlled, need to step up

- Adults and children over 5: o Trial of LABA is first option

- If ineffective, optimisation of steroid dose (up to $800 \mathrm{mcg}$ adults, $400 \mathrm{mcg} 5-12$ years) and trial of LTRA or theophylline

- Children under 5:

o Trial of LTRA (ages 2-5)

- Referral to respiratory specialist (under 2)

- If control remains poor, can move to step 4: high doses of inhaled steroid $(<2000$ mcg adults, $<800 \mathrm{mcg}$ in children aged 5-12) and a sequential trial of add-on therapy (LABA, LTRA, theophylline, oral B2-agonist bronchodilators)

- Maintenance oral steroids are indicated at step 5 only after assessment by a respiratory specialist

- When considering increasing phamacotherapy always check:

O Compliance

O Inhaler technique

O Treatment acceptability

o Patient understanding and expectation

\section{Table 3.2: Starting treatment}

- Start at pharmacological step appropriate to severity of presentation

- All patients should have a short-acting B2-agonist bronchodilator for PRN rescue medication

- In mild cases, start on PRN inhaled B2-agonist bronchodilator alone (step 1) and monitor symptoms and lung function

- Step up to regular inhaled steroids (step 2) if:

o Using 32 -agonist bronchodilator $>2$ times/day

o Using 2 or more canisters of $\beta 2$-agonist bronchodilator/month

o Nocturnal symptoms

O Recent exacerbation

O Exercise induced symptoms

- Start immediately at higher steps (e.g. standard doses of inhaled steroids (step 2), or with concomitant add-on therapy (step3) if the patient presents with more severe symptoms

- Acute severe presentations may require short-term oral steroids to attain control

- Step up if uncontrolled or partially controlled

- Step down to minimal effective treatment if stable for three months or more 
are the only bronchodilator recommended for use in the under 5 age group.

Although alternatives such as ipratropium bromide, theophyllines and oral $\beta 2$-agonist bronchodilators have evidence of effectiveness as rescue medication, they work more slowly and have more side-effects.

Therefore all patients with symptomatic asthma should have a short-acting 32 -agonist bronchodilator available for use when necessary.

\section{Inhaled steroids}

The powerful evidence for inhaled steroid treatment underlies the recommendation that standard doses of this class of drugs are the recommended preventer treatment for patients of all ages.

They should be prescribed for all patients with recent exacerbations, nocturnal asthma, impaired lung function or using rescue medication more than two to three times daily according to these guidelines, although many experts feel that more than once a day should trigger a step up.

The dose of inhaled steroids, particularly in children, should be kept to the minimum effective dose, and doses above $400 \mathrm{mcg}$ of beclomethasone or equivalent in children and $800 \mathrm{mcg}$ in adults should be used with caution and close monitoring. In these cases add-on therapy should be considered as an alternative to increasing the dose of inhaled steroids.

Advice on the pharmacological options in patients uncontrolled on standard doses of inhaled steroids is provided (see Table 3.3). The recommended starting dose of inhaled steroid should be that "appropriate to the severity of asthma", a change from previous guidelines' advice to "start high and step down".

When control is achieved, efforts should always be made to "step down" the steroid dosage to the lowest effective dose. This is particularly important for children, whose doses of steroids should be kept as low as possible and who should have growth-monitoring performed.

\section{Long-acting 82-agonist bronchodilators} (LABAs)

This class of agent has been recommended in these guidelines as first choice for patients uncontrolled on standard doses of inhaled steroids in all age groups other than the under $5 \mathrm{~s}$, for whom they are not advised at present.

The efficacy and safety of these agents used in conjunction with inhaled steroids are well established for older children and adults. Combined steroid/LABA inhalers are now available, and the evidence indicates that there is no difference in efficacy in using these agents separately or in combination devices. Therefore other concerns, such as cost, dosage flexibility, patient preference and compliance issues come into consideration.

\section{Leukotriene receptor antagonists (LTRAs)}

These agents were not available when the previous guideline was published, and so make their first appearance in the new guideline. ${ }^{1}$

The high grade of evidence for their effectiveness as add-on and as monotherapy confirm that they are useful agents, but their precise positioning remains difficult due to a paucity of high-quality head-to-head comparative studies with other therapeutic options.

They are positioned as an option at step 3 after a trial of LABAs and optimising the inhaled steroid dosage, and as an option at step 4 in adults and older children. In the under 5 age group, however, they have been positioned as the main add-on option at step 3 in children uncontrolled on standard doses of steroids.

There seems, therefore, little justification in banning or discouraging the use of this class of drugs in primary care, as has occurred in some parts of the country.

\section{Other add-on therapy}

Phamacotherapy with other traditional agents such as theophyllines, anticholinergics and chromones can be considered, but generally these agents play a minor role in modern asthma management. They 
are less effective, have more side-effects or have less convenient dosage regimes than previously considered options.

Theophyllines are however worth a therapeutic trial in sequence with other add-on agents at step 4.

Oral steroids remain an option in severe asthma at step 5, but this should probably occur under the supervision of a respiratory specialist due to major adverse outcomes. Strenuous efforts should be made to minimise the dosage by the use of inhaled steroids and add-on agents.

Finally, novel agents such as the long-acting anticholinergic tiotropium, anti-IgE monoclonal antibodies and the steroid mometasone are mentioned as treatment options soon to appear, although we lack evidence to help us position them at present.

\section{Stepwise management}

The familiar five steps of previous guidelines and the stepwise management structure have been maintained in the new guidelines, although the content and presentation of the steps have changed radically. Particularly at step 3 , the passing of the years seems to have made things more, rather than less, complicated.

Perhaps the most noticeable change is that the pharmacological asthma management steps have been separated out into three age-bands: less than 5 years old, 5-12 years old and over 12. Health professionals may be used to thinking in terms of adult and paediatric management based on previous guidelines, but this division into three age groups clarifies the major differences in pharmacological management pathways in these groups.
Since the younger paediatric population generates much of the burden of asthma in primary care, doctors and nurses need to think along different care pathways when faced with young asthmatics. The guidelines recommend starting treatment "at the step most appropriate to the initial severity of asthma" and to step up and down as necessary to maintain control on the lowest effective treatment.

As ever, it is necessary to consider compliance, inhaler technique and trigger factors before initiating new drug treatment.

\section{Audit}

Several important practical points on pharmacological management that are readily available for audit in general practice arise, and some are summarised in Table 7.5 (See Page 27).

\section{Summary}

The major message for the pharmacological management of asthma, in these new guidelines, is that inhaled steroids are the most effective firstline preventative treatment for all but the mildest asthma.

Patients uncontrolled on "standard" doses of steroid $(<800 \mathrm{mcg}$ beclomethasone or equivalent in adults, $<400 \mathrm{mcg}$ in children) should have trials of "add-on" therapy rather than increased doses of steroids.

The add-on agents of choice are:

- a LABA in adults and older children and

- an LTRA in children under 5 years

The positioning and use of LABAs and LTRAs are made clearer, although evidence is incomplete in some areas.

Several important practical points on pharmacological management that are readily available for audit in general practice arise, and some are summarised in Table 7.5 See Page 27). 


\section{Section 4, Education, self-management and compliance -practical implementation}

\begin{tabular}{|l|}
\hline Key messages \\
- Patient education, self-management and \\
compliance form a complete package that \\
underpins and supports all aspects of asthma \\
care. They should be addressed in all asthma \\
consultations and encounters. \\
- Asthma education should focus on the develop \\
ment of asthma management skills and \\
promote partnerships between the health \\
professional and the patient/carer.
\end{tabular}

\section{Introduction}

Patient education, self-management and compliance issues and solutions cannot be separated. They should be seen as part of a complete package that underpins and supports all aspects of asthma care. They are critically connected to diagnosis and pharmacological treatment and should be addressed in all asthma consultations and encounters.

\section{A key message in the BTS/SIGN British Guideline on the management of asthma ${ }^{1}$ is that patient education for everyone with asthma, and their carers, should emphasise the development of asthma management skills. Self-management training and asthma action plans are a critical part of the process. \\ Providing information is important, but needs to be supplemented with actions and strategies that promote partnerships between the health professional and the patient and family, and involve the patient and family in the decision- making process.}

The term compliance, while familiar, implies a rather traditional model of prescriptive care in which the patient follows the doctor's orders.

The new guidelines promote the use of the term "concordance". This is intended to convey a respect for both parties, the patient and the health professional, and their views and positions.

In this model, non-concordance implies the inability of both parties to come to a mutual understanding, not merely a failure of the patient to follow the doctor's orders. ${ }^{4}$

Working toward a concordant model in asthma care is relevant to all aspects of the new guidelines, but is particularly so when looking at developing partnerships.

\section{Rationale}

There is reasonably consistent evidence that for people with moderate to severe disease, structured asthma education/self-management training in conjunction with appropriate asthma treatment is associated with improved health outcomes. $1,5,6$

\begin{abstract}
Asthma action plans (also known as selfmanagement plans) are a critical component of structured asthma care. ${ }^{1}$
\end{abstract}

It is also clear that many people with asthma do not use their treatment as prescribed. This is not simply explained by intentional noncompliance. ${ }^{1,7}$ It is more likely that it reflects their lay beliefs about asthma and medication, and possibly loopholes in the supporting information and training provided by health professionals.

Therefore it is likely that an investment of time and planning around education, self-management and concordance will make a difference.

Helping people with asthma, and their families, to develop asthma management skills

Helping people to develop the essential asthma skills does not have to be complicated. It can be easily broken down into small manageable segments, covered over a series of appointments, or during opportune encounters with the patient. Each person with asthma is different, and will see his/her disease in a unique way. 
The list in Table 4.1 addresses the skills and topics important for people with asthma. The guidelines suggest that health professionals tailor these to individual patient requirements. This list may be used flexibly to negotiate with patients the areas that they see as the highest priority for them.

\section{Promoting partnerships and good} communications

The concept of working in partnership echoes the philosophy of "concordance". The most effective way of promoting a partnership is to show recognition of the priority areas the patients view as important to them.

Combined with focused asthma education good communication strategies can lead to improved health outcomes ${ }^{9}$ (see Table 4.2 for a practical guide to try out during consultations). Maximising efficiency of the asthma consultation will increase patient satisfaction, and is more likely to shorten than extend the time scale.

\section{Table 4.1 Education and management of asthma}

- Provide basic asthma information. This will both compliment and reinforce what you say during the consultation/meeting. High-quality non-promotional information is available from the National Asthma Campaign website (www.asthma.org.uk).

Alternatively put together your own, but this can be time-consuming and costly. Ask colleagues at your local specialist centres who may have something you can use. If you share the care of patients then using the same source information reduces the chance of conflicting messages.

- Support the development of self-regulating skills. People with asthma need to develop a repertoire of skills to successfully manage their disease. ${ }^{8}$ This involves being able to see changes in the asthma, react accordingly and judge whether the reaction helped. Provide and teach the use of monitoring tools. This underpins the use of an asthma plan that you will provide later. Peak flow meters and symptom lists are the best available at present.

- Provide an asthma action plan. This is a key component underpinning all good asthma care. The design of the plan is less critical than the content.

An example is available from the National Asthma Campaign, as part of their "Be in Control"' package (downloadable from the website - www.asthma.org.uk/control).

Plans can be symptom or peak-flow based, depending on age and ability.

Negotiate with the patient. Peak flows are less popular than symptoms, but both are effective means for patients to assess deterioration and improvement in their asthma. ${ }^{1}$

Traditionally health professionals complete asthma plans. Consider supporting the patient, or carer, to complete it. This will provide a deeper insight into their comprehension of the treatment. Identifying areas of uncertainty in a non-threatening way helps you to clarify where to target with future information and support.

- Check inhaler device use. Selecting the correct device and becoming competent in its use is of paramount importance. Reinforce correct use and understanding of drug types at every meeting. ${ }^{1}$ Have the patient or carer show you, correct any faults, repeat until correct technique is mastered. 
Table 4.2: Suggestions for communication and discussion in asthma consultations*

1. Show non-verbal attentiveness

2. Give non-verbal encouragement

3. Give verbal praise for things well done

4. Maintain interactive conversation

5. Find out underlying worries/concerns

6. Give specific, reassuring information

7. Tailor medication schedule to patient's/ family's routine

8. Reach agreement on short-term goal

9. Review the long-term therapeuetic goal

10. Help the patient or parent to use criteria for making decisions about asthma management

*Reproduced from Clark et al. Impact of education for physicians on patient outcomes. Pediatrics 1998;101(5):831-836.

\section{Identifying barriers to successful asthma control}

Barriers to successful asthma control lead to poor outcomes. They can largely be categorised into three types: treatment related, health professional related and patient related. ${ }^{10}$

The treatment regimes for asthma can be complex, and are usually long-term. Not surprisingly patients often show preferences for treatments, which work quickly.

Less attention has been paid to health professional-related barriers yet they are easily identified. They are not simply about time. More often they
Table 4.3 Practical tips for enhancing successful asthma control

- Agree on asthma advice and asthma care package within practice or asthma team and try to adhere to this

- Identify and maintain follow-up for priority patients (perhaps start with those seen recently as emergencies, attendees at the out-of-hours services, recent hospital admissions, and the under $5 \mathrm{~s}$ )

- Try to ensure patients see the same health professional wherever possible. This may enhance the chances of developing partnerships. It can positively influence patient motivation levels and increases patient satisfaction with consultation

- Establish treatment goals together with the patient or carer

- Simplify drug regimes (whenever possible)

- Be persistent, recall patients who miss appointments, increase contact with patients with difficult-to-control asthma

relate to appointment systems that don't suit the patient, lack of professional interest and expertise, patients seeing many different health professionals, and generally not experiencing continuity of care.

Patient-related barriers are usually around misunderstanding. They may be associated with disease severity (mild asthma may be less motivating), and undoubtedly reflect individuals' beliefs and views about their disease. These are not easy to identify or address. 


\section{Section 5}

\section{Uncontrolled asthma in general practice}

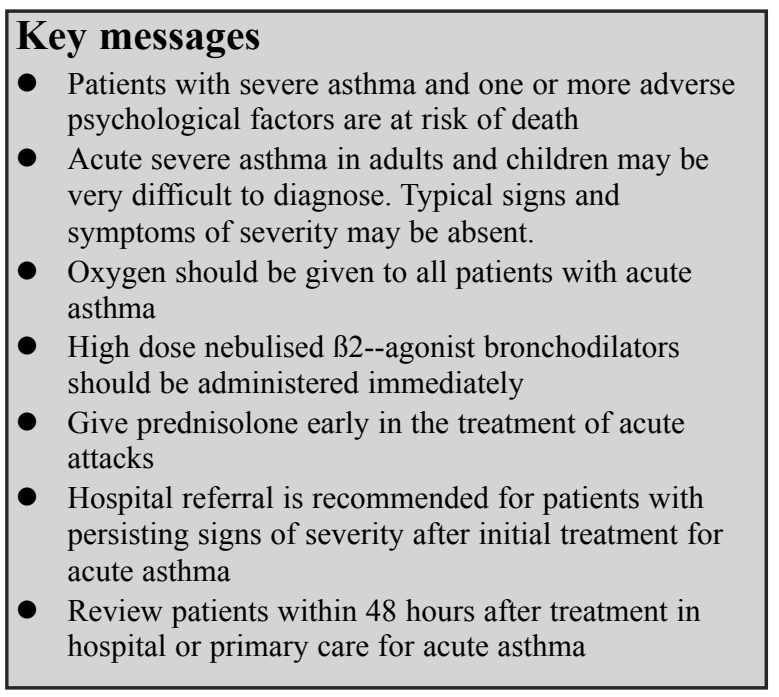

factors that put patients at risk are listed in Table 5.1.

Most severe acute asthma attacks develop slowly over periods exceeding six hours and there is therefore enough time for families and patients to seek help and for appropriate treatment. Therefore it is essential that patients be taught when to worry and seek help for their asthma. Ideally, patients are provided with a written self -management plan, to include a peak flow meter if appropriate.

Acute asthma in the BTS/SIGN British Guideline on the management of asthma has been divided into adult and children's sections. Here the recommendations and conclusions common to all age groups are

\section{Introduction}

In many cases, asthma death can be prevented if patients' families and health professionals recognise the danger signs. The most important presented first, followed by information specific to particular age groups.

Acute asthma can be diagnosed on the basis of

Table 5.1: Patients at risk of developing near fatal or fatal asthma (from guidelines ${ }^{1}$ with permission)

A combination of severe asthma recognised by one or more of:

- previous near fatal asthma e.g. previous ventilation, acidosis, previous attack related pneumothorax or pneumomediastinum

- previous admission for asthma especially if in the past year

- requiring three or more classes of asthma medication

- heavy use of $\beta 2$-agonist bronchodilator

- repeated attendances at $A \& E$ for asthma care especially if in the past year

- brittle asthma
And adverse behavioural or psychosocial features recognised by one or more of:

- non-compliance with treatment or monitoring

- failure to attend appointments

- self-discharge from hospital

- psychosis, depression, other psychiatric illness or deliberate self-harm

- current or recent major tranquilliser use

- denial

- alcohol or drug abuse

- obesity

- learning difficulties

- employment problems

- income problems

- social isolation

- childhood abuse

- severe domestic, marital or legal stress 
response to medication, lung function measurements and clinical examination.

\section{Table 5.2: Recognising uncontrolled asthma}

\section{Response to medication}

Anyone with asthma symptoms (cough, wheeze and difficulty in breathing):

- who is not getting relief from their usual bronchodilator or

- whose response to their bronchodilator does not last for four hours is in danger of developing an asthma attack

\section{Peak flow indicators}

- Widening gap between morning and evening readings

- Variation in readings from day to day

- Early morning dips

- Dropping readings

\section{Clinical findings}

- The main signs are wheezing, breathlessness, tachypnoea and tachycardia. However none of these signs specifically indicate a diagnosis of asthma and their absence does not exclude a severe attack

- Fever may be present if the attack has been precipitated by an infection

Once the diagnosis of acute asthma has been made in primary care, the clock starts ticking: the surgery is put on hold and patients with booked appointments need to be advised there may be a delay.

The management of the acute patient follows a sequence of events:

- treatment

- assessment of the severity of the attack

- a decision regarding the need for hospital admission

\section{Acute asthma in adults}

Recognition of at-risk patients is vital in prevention of asthma deaths. Patients with adverse psychosocial factors are particularly at risk; these are listed in Table 5.1

\section{Markers of severity}

Severity of acute asthma in adults can then be assessed according to table 5.3.

Table 5.3 Levels of severity of acute asthma exacerbations (from guidelines ${ }^{1}$ with permission)

Near fatal

Raised $\mathrm{PaCO}_{2}$ and/or requirasthma ing mechanical ventilation with raised inflation pressures

Life-threatening Any one of the following in a asthma patient with severe asthma:

\begin{tabular}{|c|c|}
\hline $\begin{array}{l}\text { - } \mathrm{PEF}<33 \% \\
\text { best or } \\
\text { predicted } \\
\text { - } \mathrm{sPO}_{2}<92 \% \\
\text { - } \mathrm{PaO}_{2}<8 \mathrm{kPa} \\
(\mathrm{with} \text { normal } \\
\left.\mathrm{PaCO}_{2}\right) \\
\text { - silent chest } \\
\text { - cyanosis } \\
\text { - feeble } \\
\text { - respiratory ef }\end{array}$ & $\begin{array}{l}\text { - bradycardia } \\
\text { - dysrhythmia } \\
\text { - hypotension } \\
\text { exhaustion } \\
\text { - confusion } \\
\text { - coma }\end{array}$ \\
\hline
\end{tabular}

Acute severe asthma

Any one of:

- PEF $330-50 \%$ best predicted

- respiratory rate $\geq 25 / \mathrm{min}$

- heart rate $\geq 110 / \mathrm{min}$

- severe dyspnoea

- inability to complete sentences in one breath

\section{Moderate exacerbation}

- increasing symptoms

- PEF $50-75 \%$ best or predicted

- no features of acute severe asthma

\section{Brittle asthma}

Type 1: wide PEF variability ( $>40 \%$ diurnal variation for $50 \%$ of the time over a period $>150$ days) despite intense therapy

Type 2: sudden attacks without an obvious trigger on a background of apparently well-controlled asthma 
Patients with respiratory symptoms may have acute asthma and should be assessed by a doctor or nurse trained in asthma care.

\section{Assessment:}

Lung function measurements: peak expiratory flow (PEF) and $\mathrm{FEV}_{1}$ are used for this purpose, PEF being the most convenient in primary care. Ideally, patients should be aware of their Best Ever PEF and this should be recorded in the records. Failing this, use the predicted value appropriate for the meter used.

- Good practice point: A current PEF reading, expressed as a percentage of the best (or predicted), is a good indicator of severity of airflow obstruction. $(<33 \%=$ life-threatening asthma; $33-50 \%=$ acute severe asthma; $50-75 \%=$ moderate asthma exacerbation)

\section{Pulse oximetry}

- Oxygen saturation $\left(\mathrm{SpO}_{2}\right)$ reflects the adequacy of ventilation and is helpful in determining the need for and adequacy of oxygen therapy. The $\mathrm{SpO}_{2}$ also helps the clinician decide whether arterial blood gases are needed (i.e. if below 92\%). It is important that $\mathrm{SpO}_{2}$ is measured before any treatment is administered; the level will often increase dramatically after treatment. A low pre-treatment saturation, below $92 \%$, usually indicates a need for hospital referral

- Chest x-ray and pulsus paradoxus are not helpful in assessing patients with acute asthma

\section{Immediate treatment}

- Oxygen should be given to all patients with acute asthma

- High dose nebulised B2-agonist bronchodilators should be administered immediately and at 15-30 minute intervals, either:

O by wet nebulisation* or

O via a spacer inhaler

- Nebulised ipatropium (or via spacer)

- Give systemic steroids to all adults with acute asthma

- Doses of 40-50mg daily are advised for adults (either as prednisolone $5 \mathrm{mg}$ or $25 \mathrm{mg}$ tablets).
Continue systemic steroid treatment for at least five days or until recovery

- Routine prescription of antibiotics is not indicated for acute asthma

* Wet nebulisation is used preferably via high flow oxygen (at $6 \mathrm{l} / \mathrm{min}$ requiring a high flow regulator and oxygen driven nebuliser).

\section{Monitoring}

Pro-formas have been shown to be useful in Accident and Emergency (A\&E) departments, and therefore may be helpful in primary care, to record the progress of the attack. This may facilitate the decision-making process regarding hospital referral and also serves as a suitable record for photocopying and attaching to a referral letter if sending a patient to hospital. An example pro-forma is provided in Table 5.4.

Finally, the clinician needs to decide whether to admit the patient to hospital or continue treatment at home. The guidelines do not explicitly refer to criteria for home treatment. However, the criteria intended for use in A\&E could be used in general practice.

\section{Acute asthma in children over 2 years}

Some children with acute severe asthma do not appear distressed. One of the main problems encountered in assessing children in primary care is the absence of symptoms. It is not uncommon for a child to be assessed as being well the morning after an asthma attack. A careful history is essential to establish the pattern of asthma control over the recent weeks. A requirement for additional reliever medication, night waking due to respiratory symptoms or reluctance to participate in physical activity are indicators of poor asthma control.

\section{Markers of severity}

The clinical features of asthma severity in children are shown in Table 5.6. 
Table 5.4 A useful chart for managing asthma exacerbations in primary care

(This chart could be photocopied and included with a referral letter when admitting children to hospital. It is intended for monitoring patients in the pre-hospital setting, to act as an aide memoire as well as supplementary documentation for referral to hospital)

Name: DOB: Best Previous PEF

Date Time first seen $\mathrm{H}$

History

\begin{tabular}{|c|c|c|c|c|c|c|c|c|c|c|}
\hline Time & $\begin{array}{l}\text { Pulse } \\
\text { Rate }\end{array}$ & $\begin{array}{l}\text { Respiratory } \\
\text { rate }\end{array}$ & $\begin{array}{l}\text { Using accessory } \\
\text { muscles } \\
\text { (children) }\end{array}$ & $\begin{array}{l}\text { Amount of } \\
\text { wheezing }\end{array}$ & $\begin{array}{l}\text { Degree of } \\
\text { agitation }\end{array}$ & PEF & $\begin{array}{l}\text { Pulse Oximetry } \\
\left(\mathrm{SpO}_{2}\right)\end{array}$ & Cyanosis & Exhaustion & $\begin{array}{l}\text { Oxygen } \\
\text { flow }\end{array}$ \\
\hline $\mathrm{H}_{-}$ & & & $\begin{array}{l}\mathrm{SCM} y / \mathrm{n} \\
\text { Scallini } \mathrm{y} / \mathrm{n} \\
\text { Alae nasi } \mathrm{y} / \mathrm{n} \\
\text { Intercostals } \mathrm{y} / \mathrm{n}\end{array}$ & $\begin{array}{l}0 \\
+ \\
++ \\
+++\end{array}$ & $\begin{array}{l}0 \\
+ \\
++ \\
+++\end{array}$ & & & & $\begin{array}{l}0 \\
+ \\
++ \\
+++\end{array}$ & ${ }^{\mathrm{I} / \mathrm{M}}$ \\
\hline $\mathrm{H}_{-}$ & & & $\begin{array}{l}\text { SCM y/n } \\
\text { Scallini } y / n \\
\text { Alae nasi } y / n \\
\text { Intercostals } y / n\end{array}$ & $\begin{array}{l}0 \\
+ \\
++ \\
+++\end{array}$ & $\begin{array}{l}0 \\
+ \\
++ \\
+++\end{array}$ & & & & $\begin{array}{l}0 \\
+ \\
++ \\
+++\end{array}$ & ${ }^{\mathrm{I} / \mathrm{M}}$ \\
\hline${ }_{-} \mathrm{H}_{-}$ & & & $\begin{array}{l}\text { SCM y/n } \\
\text { Scallini } y / n \\
\text { Alae nasi } y / n \\
\text { Intercostals } y / n\end{array}$ & $\begin{array}{l}0 \\
+ \\
++ \\
+++\end{array}$ & $\begin{array}{l}0 \\
+ \\
++ \\
+++\end{array}$ & & & & $\begin{array}{l}0 \\
+ \\
++ \\
+++\end{array}$ & I $\mathrm{I} / \mathrm{M}$ \\
\hline
\end{tabular}

SCM=Sternocleidomastoid muscles

Modified from Levy \&Hilton, Asthma in Practice, RCGP publications, $4^{\text {th }}$ Ed 2000

Table 5.5: Criteria for referral or home treatment (from guidelines ${ }^{1}$ with permission)

- Admit patients with any feature of a lifethreatening or near fatal attack

- Admit patients with any feature of a severe attack persisting after treatment

- Any patient with acute severe or life threatening asthma should be referred to hospital

- After initial treatment, if patient's PEF is above $75 \%$ of Best one hour after initial treatment, patient may be treated at home unless there are:

O concerns about compliance

O living alone

o psychological problems

O physical disability or learning problems

O previous near fatal or brittle asthma

$O$ if this exacerbation persisted despite failure of oral steroids for this exacerbation

$O$ night presentation

O pregnancy
Table 5.6 Clinical features for assessment of acute asthma severity in children aged over 2 years (from guidelines ${ }^{1}$ with permission)

\section{Acute severe}

- Can't complete sentences in one breath or too breathless to feed

- Pulse $>120$ aged $>5$ years

- Pulse $>130$ aged 2-5 years

- Respiration $>30$ breaths $/$ min aged $>5$ years

- Respiration $>50$ breaths/min aged 2-5years
Life threatening
- Silent chest
- Cyanosis
- Poor respiratory effort
- Hypotension
- Exhaustion
- Confusion
- Coma 
The following clinical signs should be recorded when assessing and treating a child with acute or uncontrolled asthma (the chart in Table 5.4 may be helpful in this regard):

- Increasing pulse rate denotes worsening asthma; a fall in heart rate in life threatening asthma is a pre-terminal event.

- Respiratory rate and degree of breathlessness (e.g. too breathless to talk) help in determin ing the severity of the attack

- Use of accessory muscles of respiration

- Amount of wheezing may decrease as the severity worsens

- Degree of agitation

\section{Assessment}

Lung function measurements include PEF (in children over 5 years) and pulse oximetry and are recommended in these guidelines as essential in acute asthma.

- $\mathrm{PEF}<50 \%$ predicted or of best is predictive of a more prolonged attack

- $\mathrm{SpO}_{2}<92 \%$ on air after initial bronchodilator treatment indicates a need for intensive inpatient treatment

- Chest x-rays and arterial blood gas measurements rarely provide additional useful information

\section{Immediate treatment: children}

- Oxygen should be given to all children with life threatening asthma or $\mathrm{SpO}_{2}<92 \%$ via a tight-fitting mask or nasal cannulae, at sufficient rates to ensure normal saturations

- High dose B2-agonist bronchodilators are the first-line treatment for children with acute asthma

○ pMDI and spacer ( \pm mask) are the preferred option in mild to moderate asthma in older children and in all cases of asthma in those under 2 years old

o The dose should be tailored to the severity and the child's response

- 2-4 puffs every 20-30 minutes might be sufficient for mild to moderate asthma, although up to 10 puffs may be needed for more severe asthma.
- Give prednisolone early in the treatment of acute attacks

- Use soluble prednisolone tablets dissolved in water on a teaspoon

o $10 \mathrm{mg}$ for children under 2 years of age

O 20mg for children 2-5 years old

O $30-40 \mathrm{mg}$ for children over 5 years old

- $2 \mathrm{mg} / \mathrm{kg}$ is needed for children on maintenance steroid tablets

- Three days is usually sufficient. However, the duration of prednisolone therapy must be tailored to the individual child

- Children refractory to initial $\beta 2$-agonist treatment may respond to ipatropium bromide (nebulised, 250mcg dose mixed in with the B2-agonist solution)

- Aminophyline is not recommended in children with mild to moderate acute asthma

\section{Referral to hospital: children}

- Refer children who do not respond to treat ment with up to 10 puffs of $\beta 2$-agonist bronchodilator

- Continue to administer ß2-agonist bronchodilators as necessary whilst awaiting transfer to hospital

- Treat these children with oxygen-driven nebulised B2-agonist bronchodilators on the way to hospital

- $\mathrm{SpO}_{2}<92 \%$ on air after initial bronchodilator treatment indicates a need for intensive inpatient treatment

\section{Follow-up}

These guidelines stress the importance of following up patients treated for acute asthma, irrespective of the place of treatment or age. There is a high risk of relapse following an attack and these patients should be seen in primary care, ideally within a few days of the attack. Children should be seen by a paediatrician within a few months and adults with brittle asthma should be followed up for life by a specialist. 


\section{Section 6, Special situations - pregnancy, infants and occupational asthma}

\section{Key messages}

- A system needs to be in place to ensure that all women with asthma who register for maternity care are invited to see their GP or practice asthma nurse for routine monitoring

- Discuss the diagnostic problems in wheezy infants openly with parents and agree management plans

- Record the diagnostic process clearly in wheezy infants' records. A prescription for an inhaler used as a trial of therapy may "label" the infant as asthmatic - even if the trial was negative

- Clinicians should consider the possibility of an occupational cause for adult onset asthma and should refer any patient identified

Three groups are highlighted by the BTS/SIGN British Guideline on the management of asthma ${ }^{1}$ as presenting specific challenges to clinicians:

- pregnant women whose asthma is often under-treated

- people with occupational asthma when the sensitising agent is often unrecognised

- infants where both the diagnosis and management are notoriously difficult

\section{Asthma in pregnancy}

The message from the guidelines is clear and simple: the medicines used to treat asthma are safe in pregnancy. The greater danger is that concern for teratogenicity may lead to under-treatment with inherent risks to both the mother and foetus. If asthma is well controlled throughout pregnancy there is little or no risk of complications. A pregnant woman with diabetes or renal failure would expect to attend a specialist clinic. Routine review of a pregnant woman for assessment of her asthma, however, is not common.

Maternity care for a woman with asthma may involve several members of the primary care team. Changing childbirth ${ }^{11}$ has encouraged midwives to take the leading role in the provision of maternity care: their knowledge of asthma management, however, may be limited. Practice nurses may have the asthma knowledge, but will rarely be aware of the pregnancy. In many practices it will be the general practitioner who is best able to ensure that the patient receives appropriate monitoring.

Although women with very severe asthma and who are at high risk of acute attacks should receive specialist care, the majority of women will be monitored in primary care. Written action plans should be discussed so that the patient can increase and decrease her own therapy to maintain the best possible control with the minimum of drug treatment. The combination of guided self-management and regular review is known to improve morbidity and reduce exacerbations. ${ }^{12}$

- A third of women will notice an improvement in their asthma. In line with the guidelines a step-down in treatment should be tried together with careful patient monitoring

- A third of women will experience increasing problems with their asthma, especially early in the third trimester. Patients may be reassured that it safe to step up treatment: inhaled steroids, both short and long acting $\beta 2$-agonist brochodilators should be used as normal. Theophyllines are safe, but leukotriene receptor antagonists (LTRAs) are not recommended because of the limited data base

- Acute asthma resulted in five maternal deaths in the three years between 1997 and $1999^{13}$ so it is of concern that there is evidence of a reluctance to use oral steroids in pregnancy. Acute asthma should be treated as normal

- Pregnant women will often want to discuss the safety aspects of their treatment and may be receptive to advice about reducing oropharyngeal deposition of inhaled medication, perhaps by using a spacer with their metered dose inhaler 
- Women with asthma should be encouraged to breast-feed as it reduces the risk of atopic disease in the baby. Clearly many factors will influence a woman's choice but all the practice team, midwives, health visitors, practice asthma nurses and general practitioners should feel confident to give the same messages: breast-feeding will benefit the baby, and asthma medications are safe for the lactating woman.

\section{Infants}

Wheezy infants are very common in primary care. Respiratory disease accounts for a third of GP consultations in children, with the highest incidence in preschool children. ${ }^{14}$ Some will have persistent asthma, many will be transient early wheezers, and a few will have other more serious pathology. ${ }^{15}$

The guidelines helpfully provide a list of symptoms not usually associated with asthma, which should prompt a search for alternative diagnoses. Knowing that the majority of infants who wheeze will "grow out of it" and the practical difficulties of establishing a diagnosis in young children will make clinicians reluctant to "label" children. Living with diagnostic uncertainty is a familiar problem for general practitioners but causes understandable concern for parents. ${ }^{16}$

The three components of the diagnostic process are similar to that in older children and adults: an appropriate history, objective evidence and a response to treatment.

- Episodic cough and wheeze, especially in the presence of atopy, are suggestive of asthma

- Lung function tests are impractical in infants in a primary care setting. Wheeze, heard by a healthcare professional should be noted in the patient's records as objective confirmation of the parent's description.

- A trial of treatment may be a useful strategy ${ }^{17}$ (see Figure 6.1). A clear response to bronchodilation will be helpful, but for more chronic symptoms a course of inhaled steroids

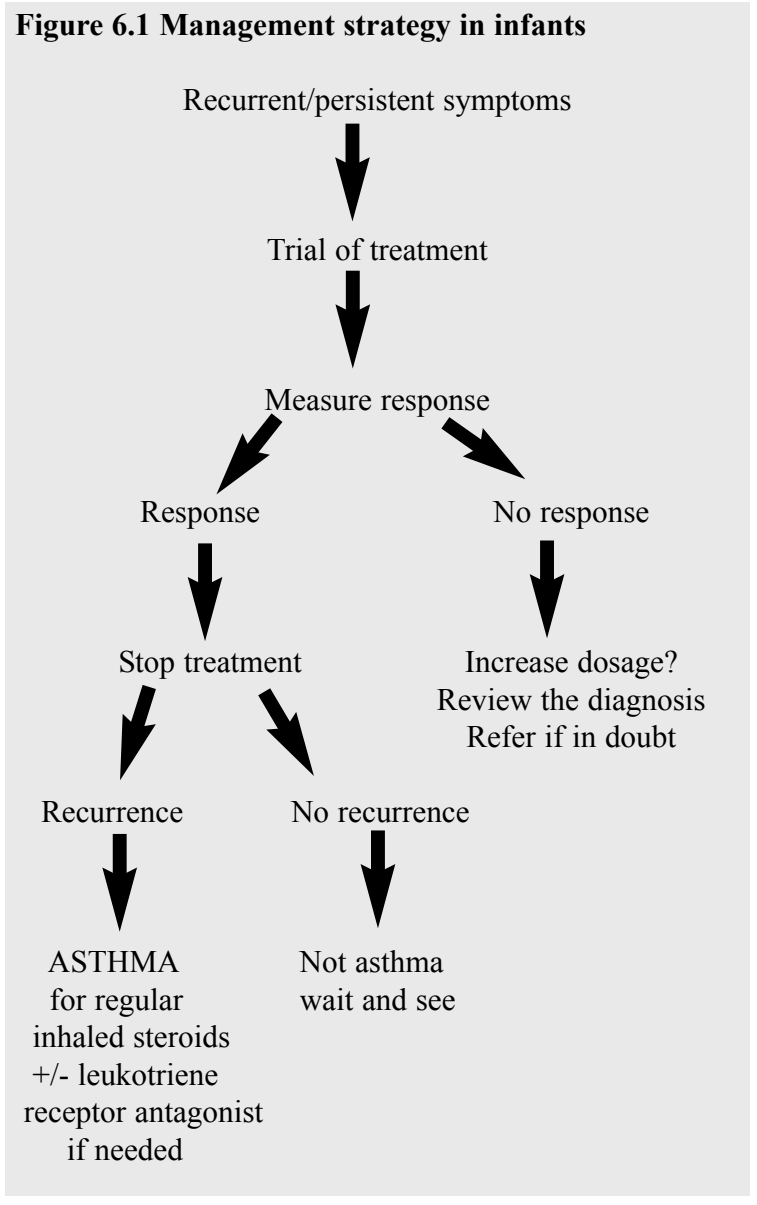

will be more appropriate. The guidelines recognise that the "reasonable starting dose" of $200 \mathrm{mcg}$ a day suggested for children may have to be increased for infants because of the practical problems of delivering adequate doses to the lung - some authors have suggested up to $800 \mathrm{mcg}$ daily for two months. ${ }^{18,19}$ A good symptomatic response supports a diagnosis of asthma, but it is important to withdraw treatment to exclude coincidental improvement. A poor response suggests that asthma is unlikely and should prompt consideration of alternative causes for the child's symptoms. Follow-up throughout the trial is crucial and the response to treatment should be clearly documented. Compliance with administering the drugs and 
follow-up is likely to be facilitated if parents understand and agree to the process. ${ }^{20}$

Inhaled steroids are the "preventer" of choice in this age group, given via a spacer (with a mask if necessary) $)^{21}$ and titrated to the lowest effective dose. There are, however, practical problems associated with treating asthma in infants. Many mothers will testify that persuading their two yearold to co-operate with treatment twice a day is nearly impossible. Referral to an asthma-trained nurse may be helpful.

The problem of unco-operative toddlers is particularly challenging in dealing with acute asthma. Facemasks on nebulisers need to be applied to the face, otherwise the inhaled dose may be reduced by $85 \% .{ }^{22}$ "Wafting" a nebuliser some inches below the chin in order to avoid upsetting a child would therefore seem unlikely to be a useful procedure.

Metered dose inhalers and spacers are as effective as nebulisers, therefore using spacers when the child is not distressed, may facilitate their use in an emergency. Oral ß2-agonist bronchodilators are ineffective.

- A common question from the parents of infants diagnosed with asthma is: "Will he grow out of it?" The guidelines provide a useful summary of the risk factors associated with persistent asthma, which may helpful when discussing the prognosis with families. Wheezy infants, particularly those whose symptoms start before the age of 2 years, have a good prognosis - the majority will have "grown out of it" before they reach their teenage years. A maternal or personal history of atopy is associated with wheeze throughout childhood. Girls and infants with severe and frequent episodes are at increased risk of lifelong disease.

\section{Occupational asthma}

Occupational asthma is under-diagnosed. Estimates suggest occupational sensitisers may account for $10 \%$ of adult onset asthma - an incidence far higher than is identified in most general practices. Although some people working in high-risk environments will have regular spirometry undertaken by occupational health nurses, primary care has a responsibility to identify the possibility of an occupational cause for asthma developing in working adults.

- Consider the possibility. Be suspicious of an occupational cause in any patient presenting with adult onset asthma

- Ask about occupation and the effect it has on asthma symptoms. The following questions, while not specific for occupational asthma, may identify those where the possibility of occupational causes should be considered: "Are you better on days away from work?" "Are you better on holiday?"

- There are several hundred recognised respiratory sensitisers. The two highest-risk occupations are paint spraying causing exposure to iso-cyanates and jobs such as industrial baking causing exposure to dust from grain and flour. Other common sensitisers are wood dust, colophony in the fumes from solder and latex (see Figure 6.2)
Figure 6.2:

Top 10 sensitisers responsible for occupational asthma

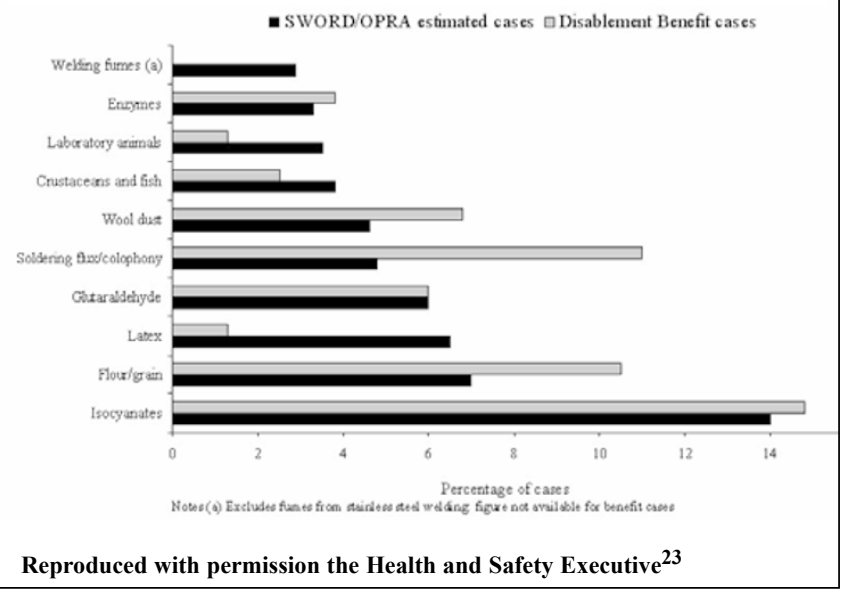


- Any patient with suspected occupational asthma should be referred for specialist assessment

- If an occupational cause is confirmed the employer will be asked to relocate the patient from the sensitiser. Ideally this should be within a year of the onset of symptoms as prolonged exposure worsens the prognosis

- Patients will be fearful of losing their jobs, though the Health and Safety Executive advise that: "Almost all cases of occupational asthma can be prevented by the use of proper controls."23 General practitioners will be aware of the stress to patients and their families caused by threats to employment. Encouraging patients to seek the advice of their union may provide practical support.

- Patients may be eligible for Industrial Injuries Disablement Benefit if they have been disabled by known sensitisers. Information is available from the benefits agency, via the local Jobcentre. It is important not delay as claims are only recognised if exposure has occurred within the past 10 years.

\section{Resources}

- The National Asthma Campaign publishes the following booklets:

o Asthma and women, which includes a section on asthma in pregnancy. http://www.asthma.org.uk/about/booklet09.php

o Asthma in the under 5's

http://www.asthma.org.uk/about/booklet08.php

o Asthma at work, which explains about occupational causes of asthma.

http://www.asthma.org.uk/about/booklet01.php
- The British Lung Foundation has a leaflet for people with occupational lung disease with information about asthma and other lung diseases. There is a section on the benefits available.

http://www.britishlungfoundation.com/info/Lung1

1_occupational.pdf

- Further information about occupational causes of asthma is available from the Health and Safety Executive.

http://www.hse.gov.uk/hthdir/noframes/asthma.htm

- Information about industrial injuries benefit may be obtained from the local Jobcentre or on line at

http://www.dwp.gov.uk/lifeevent/benefits/industrial_injuries_dis.htm\#what 


\section{Section 7 \\ Organisation of care and audit}

\section{Key messages}

- Maintain a structured system for managing asthma in the practice, to include systems for identifying and recalling patients at risk (see also Section 5)

- Create and maintain a consistent system for recording clinical data

- Incorporate audit and critical review of management of asthma in the practice routine

- Patients with previous near-fatal attacks and brittle asthma should be under specialist supervision indefinitely. They should have immediate access to a specialist unit

$\mathrm{I}$ the early 1990s many practices provided care for patients with asthma through organised clinics, run at set times and staffed by a combination of trained asthma nurses and doctors. Recently, due to workload and financial pressure, many practices provide this care in an opportunistic manner, often relying on patients attending spontaneously. The main advantage of the clinic system was that patients were clearly managed in a structured way.

The BTS/SIGN British Guideline on the management of asthma ${ }^{1}$ stress that structured clinical review of people with asthma is associated with favourable outcomes, including reduced school or work absence, as well as reduced exacerbation rates and better symptom control. As practices embrace alternative service rrangements, it becomes increasingly important to ensure that asthma patients receive a consistently high standard of proactive review, following an agreed protocol.

The guidelines recommend that a nurse with training in asthma management should review people with asthma regularly. A new development in the UK is to accredit GPs who have expertise in a particular field as GPS with a special clinical interest (GPSCIs). The possible roles of GPSCIs are being discussed. ${ }^{25}$
It is suggested that GPSCIs could review difficult cases, assess all patients after acute attacks, for instance after A\&E department treatment. They may also have a role in education, setting standards for Primary Care Trusts (PCTs) and organising local audits.

\section{Structured review}

The guidelines favour proactive rather than opportunistic review of people with asthma. This requires an accurate and current asthma register.

Ideally all asthma patients should be reviewed regularly. However if workload prevents this, practices might target at-risk groups of people (see Table 7.1 and Section 5).

Table 7.1: At-risk patients

(see also tables in Section 5)

- Children with frequent consultations with respiratory infections

- Children over 5 years with persistent symptoms of asthma

- Patients with asthma and psychiatric disease or learning disability

- Patients using large quantities of B2-agonist bronchodilators

There are a number of systems for recording information in a structured manner. These guidelines list three: the Royal College of Physicians Three Questions (see Table 7.2), the Tayside Stamp and the modified Jones Morbidity Index. Some of the data used in these systems are coded with Read codes for UK general practice computer systems. 
Table 7.2: The Royal College of Physicians Three Questions ${ }^{26}$

In the past week/month:

1. Have you had any difficulty sleeping because of asthma symptoms (including cough)? YES / NO

2. Have you had your usual asthma symptoms in the day (cough, wheeze, chest tightness or breathlessness)?

YES / NO

3. Has your asthma interfered with your usual activities (e.g. housework, work, school, etc)? YES / NO

\section{Special circumstances}

The guidelines draw attention to the complex needs of patients from ethnic minorities, those from disadvantaged groups and those with communication difficulties. Depending on the local population served, practices may need to adapt their service accordingly, perhaps by ensuring they have a system for providing interpreters and print materials in different languages. Self-management plans have been addressed in Section 4 of this supplement - these may need to be provided in different languages.

\section{Follow-up and monitoring}

Whether in hospital or in the community, followup after an attack is necessary, to establish that patients' symptoms have resolved, lung function is stable and that treatment can be safely stepped down.

Systems should be in place to identify and ensure co-ordinated management of patients across the primary/secondary care interface - for example, through enhanced communication between A\&E departments and practices when patients attend for acute or uncontrolled asthma. While many patients fail to attend follow-up appointments, these do provide an opportunity for patient education.

\section{Audit}

Clinical audit has been incorporated into day-today primary care activity in the UK. The guidelines devote a whole chapter to audit and outcomes. They stress the use of structured recording in the management of asthma patients. The use of templates using agreed computer codes is very helpful in maintaining consistent records for the purpose of audit and comparison with others.

The guidelines suggest various outcome measures for assessing both process and outcome of asthma management in primary care. These are listed in Tables 7.3 to 7.6. reproduced from guidelines ${ }^{1}$ with permission.

Table 7.3: Audit points for asthma clinics in primary care: useful for organisations such as Primary Care Trusts ${ }^{1}$

- Is there a practice nurse with a recognised diploma or who has undergone recognised training?

- How much time has (s)he for seeing patients with asthma?

- Do you have a system for identifying:

1. Children having frequent consultations with respiratory infection so that the possibility of asthma can be considered?

2. Patients with asthma and psychiatric disease or learning disability for surveillance of asthma control?

3. Those requesting B2-agonist bronchodilator inhalers frequently so that the need for other treatment (usually inhaled steroids) can be reviewed?

- How do you identify the following groups of patients in order to optimise their treatment and teach self-management skills?

1.Patients on step 3 or above

2. Those having steroid courses for acute asthma/emergency nebulisation/unscheduled appointments for asthma

3. Patients seen in A\&E or hospitalised

4.Patients seeing different doctors

- Do you have a structured record for patients with asthma that includes symptom questions?

- What is the nature of asthma-related continuing professional development (CPD) undertaken by partners in the past five years?

- Has an audit of asthma care been completed in the past year?

- Is there any evidence of changes in practice in response to findings? 


\begin{tabular}{|c|c|c|}
\hline \multicolumn{3}{|c|}{$\begin{array}{l}\text { Table 7.4: Audit dataset for acute asthma managed in primary care } \\
\text { BTS/SIGN British Guidelines on the management of asthma }{ }^{1} \text { with } \\
\text { READ Codes added) }\end{array}$} \\
\hline Audit point & Output from audit & Read Codes \\
\hline $\begin{array}{l}\text { Record the following items } \\
\text { in patients with uncontrolled } \\
\text { asthma, nebulised or attending } \\
\text { for unscheduled appointments } \\
\text { in primary care }\end{array}$ & & \\
\hline PEF measurement & \multirow{5}{*}{$\begin{array}{l}\text { Proportion of } \\
\text { patients for whom } \\
\text { these actions } \\
\text { were taken }\end{array}$} & $\mathrm{PEF}=3395$ \\
\hline $\begin{array}{l}\text { Whether oral steroids were } \\
\text { prescribed }\end{array}$ & & $\begin{array}{l}\text { Search on drug } \\
\text { prescription for } \\
\text { prednisolone }\end{array}$ \\
\hline $\begin{array}{l}\text { Whether reviewed within } \\
2 \text { weeks of acute attack }\end{array}$ & & $\begin{array}{l}\text { Seen in primary care } \\
\text { asthma clinic }=9 \mathrm{~N} 1 \mathrm{~d} \text {. }\end{array}$ \\
\hline Convalescent PEF & & $\begin{array}{l}\mathrm{PEF}=3395 \\
\text { Best } \mathrm{PEF}=\text { 339D. }\end{array}$ \\
\hline $\begin{array}{l}\text { Documented review of } \\
\text { action plan }\end{array}$ & & $\begin{array}{l}\text { Asthma } \\
\text { management plan } \\
\text { given }=663 \mathrm{U}\end{array}$ \\
\hline
\end{tabular}

While the guidelines do provide suggestions for audit points, some of these may be difficult to measure in view of the absence of appropriate READ codes. For example, the three questions proposed by the Royal College of Physicians (see Table 7.2).

Ideally, practices should use standard templates, using commonly accepted computer (Read) codes for recording diagnoses and information derived from structured review appointments. This will enhance audit and clinical governance in practices and primary care organisations.

We have made suggestions (see Table 7.6 and Section 2 of this supplement) for implementing audit through the use of appropriate entries for Read codes. The GPIAG is currently developing systems of this nature, including a minimum-data-set of Read codes for respiratory disease (see the website, http://www.gpiag.org/forum for upto-date information on these developments).

Table 7.5: Possible pharmacological management audit points for GPs 1

Have all patients had inhaled short acting B2-agonist bronchodilators prescribed for rescue use?

- How many patients are ordering two or more canisters of $ß 2$-agonist bronchodilators/month?

- How many patients are receiving maintenance or frequent oral steroids, and has a respiratory specialist assessed them?

- In children aged under 12:

- How many are on greater than $400 \mathrm{mcg} /$ day equivalent of inhaled steroid?

- Have they been recently reviewed (e.g. within six months) and has step-down been considered?

- Has add-on therapy (LABAs in children aged 5-12, LTRAs in under $5 \mathrm{~s}$ ) been considered?

- In adults and children 12 or over:

- How many patients are on greater than $800 \mathrm{mcg} /$ day equivalent of steroid?

- Have they been reviewed and step-down considered?

- Has add-on therapy (LABAs) been considered? 


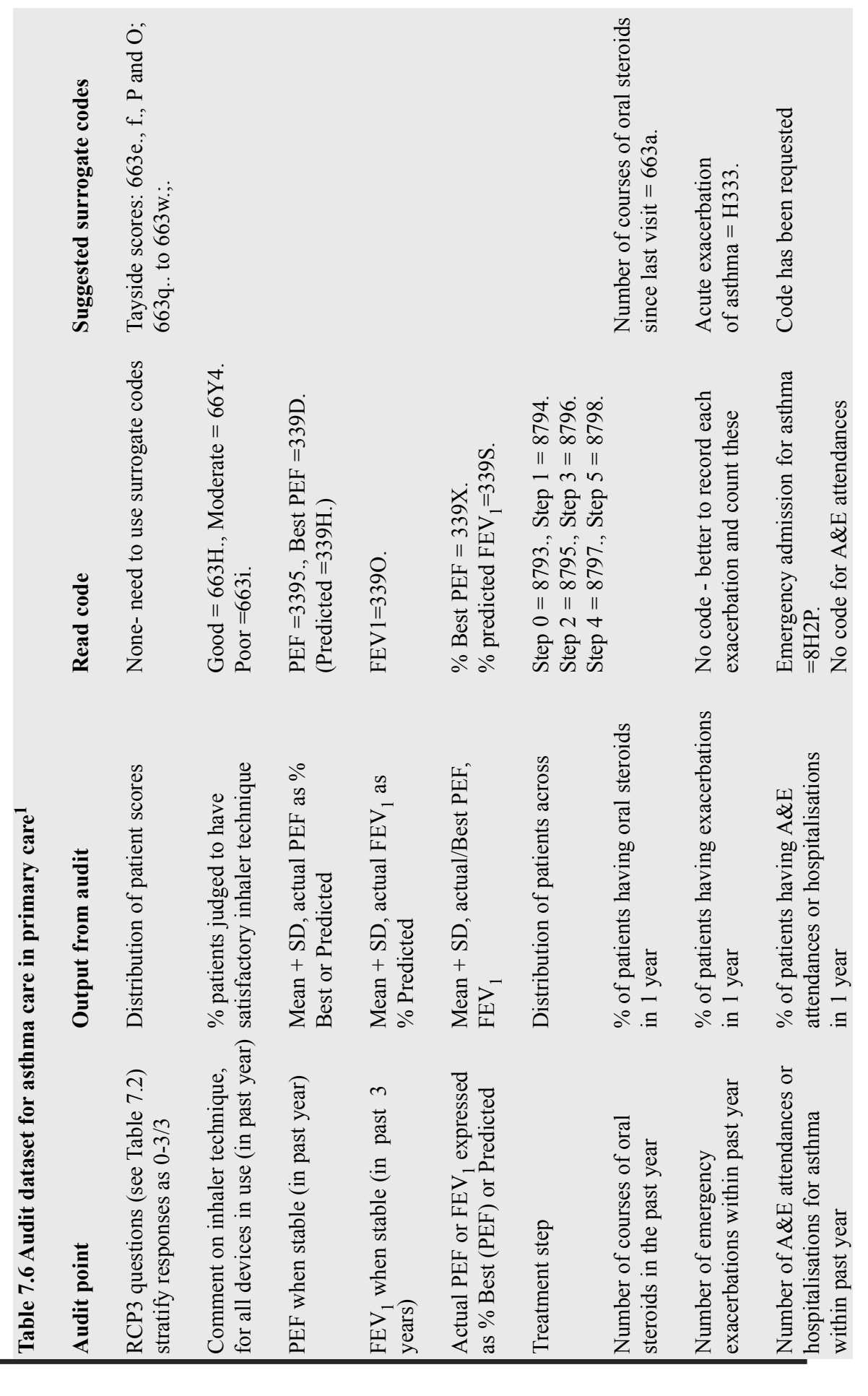



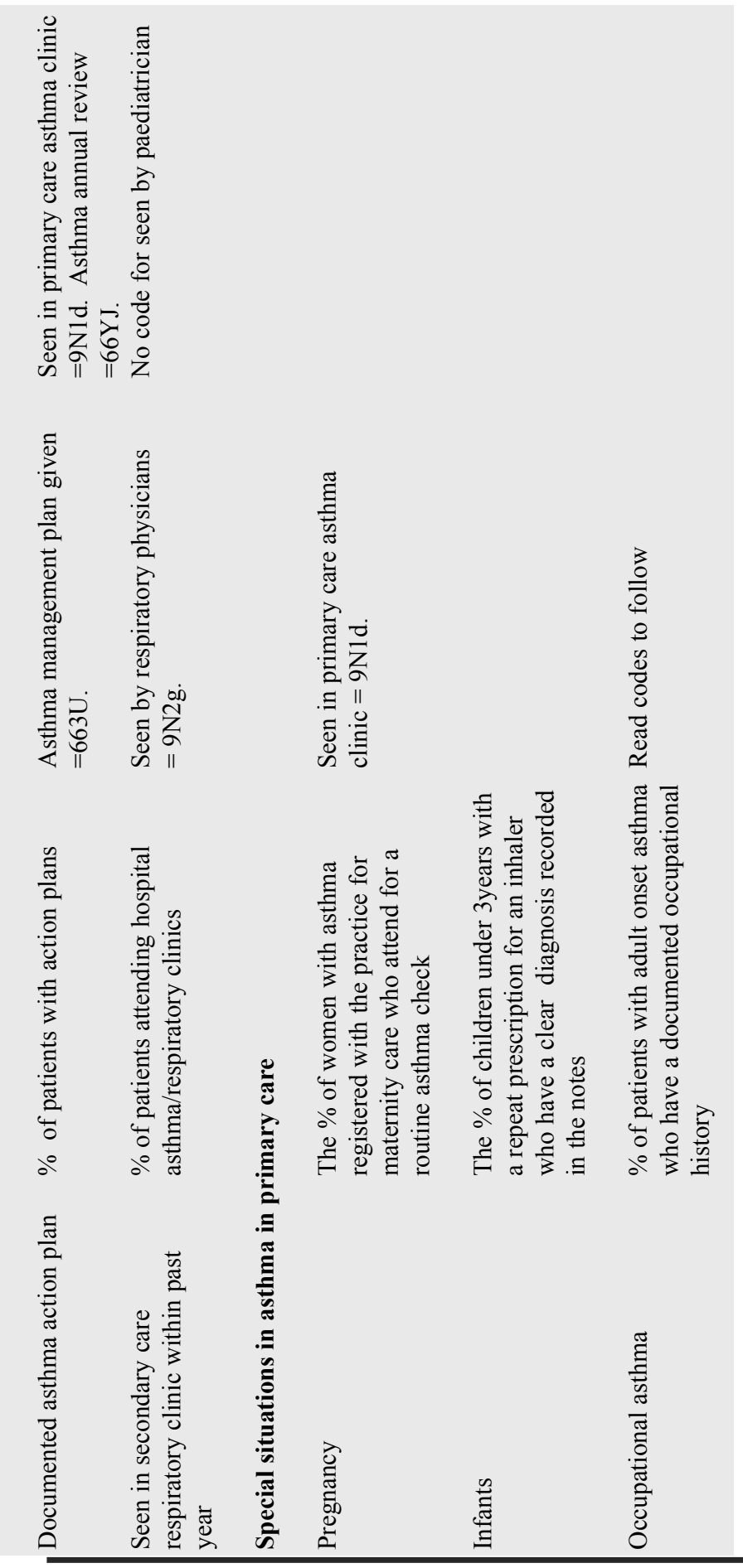


\section{References}

\section{Bibliography}

1. British guideline on the management of asthma. The British Thoracic Society/Scottish Intercollegiate Guidelines Network. Thorax 2002. In press

2. Global Strategy for the Diagnosis, Management and Prevention of Chronic Obstructive Pulmonary Disease. Executive Summary. NIH Publication No. 2701A. March 2001.

3. Bush A. Diagnosis of asthma in children under five. Asthma Gen Pract 2000;8(1):4-6.

4. Royal Pharmaceutical Society of Great Britain. From compliance to concordance: Achieving shared goals in medicine taking. London: The Society; 1997.

5. Gibson PG, Coughlan J, Wilson AJ, Bauman A, Hensley MJ, Walters E. The effects of self-management education and regular practitioner review in adults with asthma (Cochrane Review). In: The Cochrane Library, Issue 3, 1998. Oxford: Update Software.

6.Cote J, Bowie DM, Robichaud P, Parent JG, Battisti L, Boulet LP. Evaluation of two different educational interventions for adult patients consulting with an acute asthma exacerbation. Am J Respir Crit Care Med 2001;163:1415-9.

7. Osman LM, Friend JAR, Legge JS, Douglas JG. Requests for repeat medication prescriptions and frequency of acute episodes in asthma patients. $J$ Asthma 1999;36:449-457.

8. Clark NM, Partridge M. Strengthening asthma education to enhance disease control. Chest 2002;121:1661-1669.

9. Clark NM, Gong M, Schork MA, Evans D, Roloff D, Hurwitz M, Maiman L, Mellins RB. Impact of education for physicians on patient outcomes. Pediatrics 1998;101(5):831-836.

10. Bender BG. Overcoming barriers to non-adherence in asthma treatment. $J$ Allergy Clin Immunol 2002;109:S554-9.

11. Department of Health (1993) Changing childbirth. Report of the Expert Maternity Group (Cumberlege Report). HMSO: London 12.Gibson PG, Coughlan J, Wilson AJ, et al. Selfmanagement education and regular practitioner review for adults with asthma (Cochrane Review).
Cochrane Library 2000; 1: Oxford: Update Software.

13. Lewis G, editor. Why mothers die 1997-1999.

The fifth report of the confidential enquiries into maternal deaths 1997-1999. London: RCOG Press; 2001.

14. Office for National Statistics. Morbidity Statistics from General Practice 1991-92, patient records.

15. Martinez FD. Development of wheezing disorders and asthma in pre-school children. Pediatrics 2002;109:362-7.

16. National Asthma Campaign. Sleepless nights, anxious days. National Asthma Campaign 2002. 17. Stephenson P. Management of wheeze and cough in infants and pre-school children in primary care. Prim Care Respir J 2002,11(2):42-4. 18. Cochran D. Diagnosing and treating chesty infants. $B M J$ 1998;316:1546-7.

19. Bush A. Diagnosis of asthma in children under five. Asthma Gen Pract 2000;8(1):4-6.

20. Price J, Leaver L. ABC of psychological medicine: beginning treatment. $B M J$ 2002;325:33-35.

21. National Institute for Clinical Excellence. Guidance on the use of inhaler systems (devices) in children under the age of 5 years with chronic asthma. Technology Appraisal Guidance No 10. 22. British Thoracic Society. Current best practice for nebuliser treatment. Thorax 1997; 52(S2): S1105.

23. Health and Safety Executive. Health

Directorate asthma page.

http://www.hse.gov.uk/hthdir/noframes/asthma.htm (accessed 29th Sept 2002).

24. Health and Safety Executive. Health and safety statistics 2000/1. Part II Occupational ill-health statistics. HMSO 2001.

25. Williams S, Ryan D, Price D, Langley C, Fletcher M, Everdon P. Br J Gen Pract 2002;52:838-43.

26. Measuring clinical outcome in asthma - a patient-focused approach. Eds Pearson M and Bucknall C.. Royal College of Physicians 1999. ISBN 180160972. 


\section{Key Messages}

\section{Diagnosis of asthma}

- Objective tests should be used where possible to confirm a diagnosis of asthma before long-term therapy is started

- Clinicians should record the criteria used to make the diagnosis

- Failure to respond to asthma therapy should prompt further consideration

\section{Pharmacological management - chronic asthma} and children

- Outcomes of asthma care remain sub-optimal in the UK, and the BTS/SIGN British Guideline on the management of asthma ${ }^{1}$ provide encouragement and assistance in improving the way we treat our patients

- Asthma is a variable disease and not all patients will respond in the same way. Therefore therapeutic trials, observation of results and trial of alternative options (and discontinuation of ineffective ones) are needed

- GPs and practice nurses, the front-line asthma care providers in the community, need to be aware of patients' agendas, their hopes and fears about their asthma and its treatment, and be prepared to be flexible and to respond appropriately

- The guidelines provide an opportunity to review the management of patients with asthma in primary care, which should help to improve outcomes

- The importance of inhaled steroids is emphasised. However the use of high doses of steroids may not be the best option in many situations, and should be carefully monitored, particularly in children. Doses of greater than $400 \mathrm{mcg} /$ day should not be used in children under 5 without specialist assessment and without a trial of a leukotriene receptor antagonist (LTRA).
Education, self-management and compliance -practical implementation

- Patient education, self-management and compliance form a complete package that underpins and supports all aspects of asthma care. They should be addressed in all asthma consultations and encounters.

- Asthma education should focus on the develop ment of asthma management skills and promote partnerships between the health professional and the patient/carer.

\section{Uncontrolled asthma in primary care}

- Patients with severe asthma and one or more adverse psychological factors are at risk of death

- Acute severe asthma in adults and children may be very difficult to diagnose. Typical signs and symptoms of severity may be absent.

- Oxygen should be given to all patients with acute asthma

- High dose nebulised B2-agonist bronchodilators should be administered immediately

- Give prednisolone early in the treatment of acute attacks

- Hospital referral is recommended for patients with persisting signs of severity after initial treatment for acute asthma

- Review patients within 48 hours after treatment in hospital or primary care for acute asthma

\section{Special situations}

- pregnancy, infants and occupational asthma

- A system needs to be in place to ensure that all women with asthma who register for maternity care are invited to see their GP or practice asthma nurse for routine monitoring

- Discuss the diagnostic problems in wheezy infants openly with parents and agree management plans

- Record the diagnostic process clearly in wheezy infants' records. A prescription for an 


\section{Key messages continued}

inhaler used as a trial of therapy may "label" the infant as asthmatic - even if the trial was negative

- Clinicians should consider the possibility of an occupational cause for adult onset asthma and should refer any patient identified

\section{Organisation of care and audit}

- Maintain a structured system for managing asthma in the practice, to include systems for identifying and recalling patients at risk (see also Section 5)
- Create and maintain a consistent system for recording clinical data

- Incorporate audit and critical review of management of asthma in the practice routine

- Patients with previous near-fatal attacks and brittle asthma should be under specialist supervision indefinitely. They should have immediate access to a specialist unit

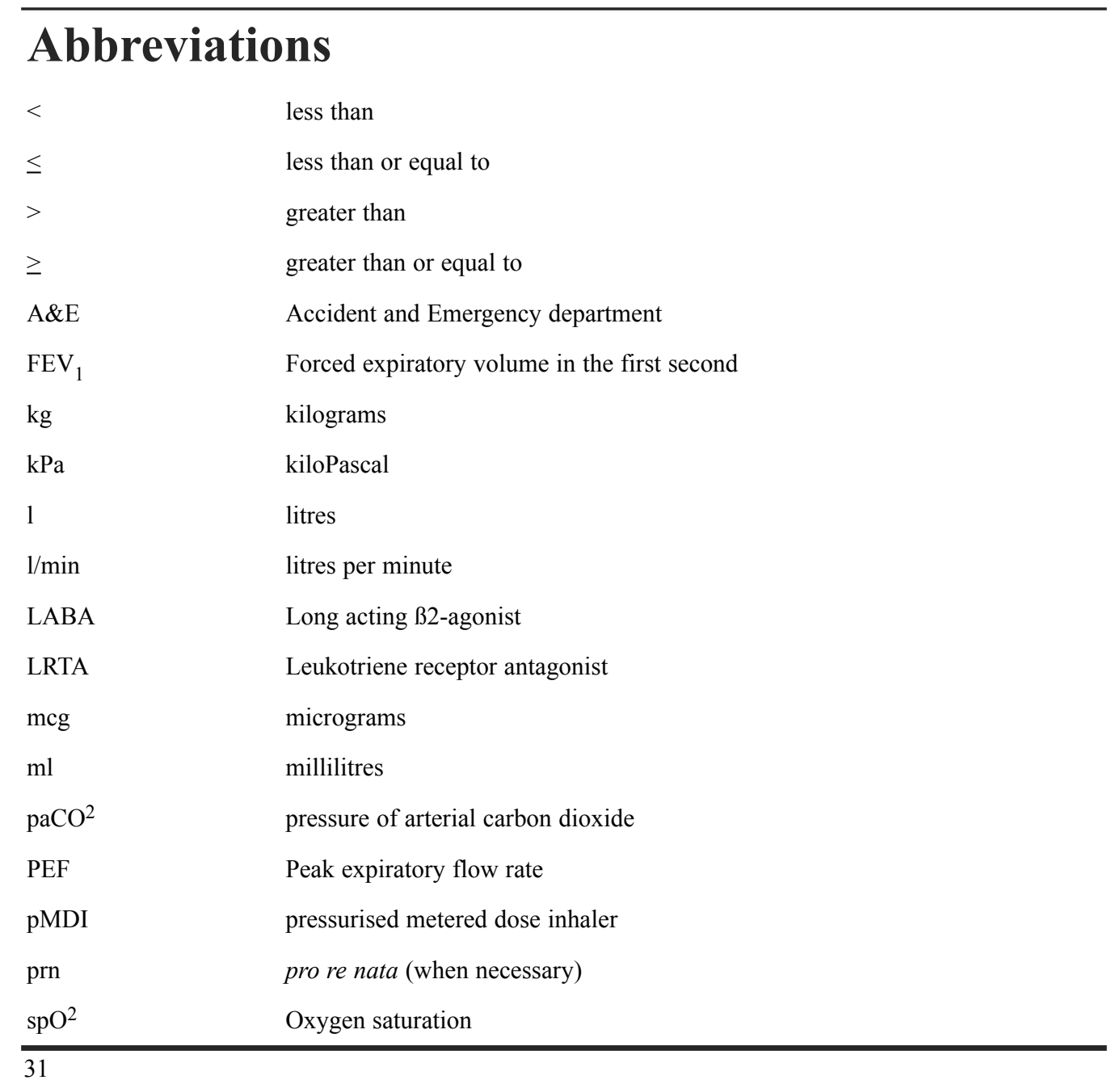




\section{Directory of Tables and Figures}

Figure 1.1 More than 16,000 papers were reviewed and graded according to the

SIGN methodology, resulting in graded recommendations

Table 1.1 SIGN evidence grading table 3

Table 1.2 SIGN grades of recommendation 3

Table 2.1 PEF variability: an example 5

Table 2.2 Indications for referral of children with suspected asthma for specialist $\quad 7$ opinion/further investigation

Table 3.1 Aims of pharmacological management 8

Table 3.2 Starting treatment 9

Table 3.3 Step 3 and above 9

$\begin{array}{lll}\text { Table 4.1 Education and management of asthma } & 13\end{array}$

Table 4.2 Suggestions for communication and discussion in asthma consultations $\quad 14$

Table 4.3 Practical tips for enhancing successful asthma control 14

Table 5.1 Patients at risk of developing near fatal or fatal asthma 15

Table 5.2 Recognising uncontrolled asthma 16

Table 5.3 Levels of severity of acute asthma exacerbations 16

Table 5.4 A useful chart for managing asthma exacerbations in primary care $\quad 18$

Table 5.5 Criteria for referral or home treatment 18

Table 5.6 Clinical features for assessment of acute asthma severity in children aged $\quad 18$ over 2 years

Figure 6.1 Management strategy in infants 21

Figure 6.2 Top 10 sensitisers responsible for occupational asthma 23

$\begin{array}{lll}\text { Table } 7.1 & \text { At-risk patients } & 24\end{array}$

Table 7.2 The Royal College of Physicians Three Questions 25

Table 7.3 Audit points for asthma clinics in primary care: useful for organisations 25

Table 7.4 Audit dataset for acute asthma managed in primary care BTS/SIGN Guideline 26 on the management of asthma with Read codes added

Table 7.5 Possible pharmacological management audit points for GPs 26

Table 7.6 Audit dataset for asthma care in primary care $\quad 27$ 
Editor: Dr Mark Levy

News Editor: Dr Paul Stephenson

Publications Manager: Tricia Bryant

Editorial Board:

Dr Chris Griffiths

Dr Robert McKinley

Dr Aziz Sheikh

International Editorial Advisers:

Dr Carlos Gonçalves (Portugal)

Dr Thomas Hausen (Germany)

Dr Svein Hoegh Henrichson (Norway)

Dr Alan Kaplan (Canada)

Dr Line Kleinnebreil (France)

Dr Marianne Ostergaard (Denmark)

Dr Gunnar Johansson (Sweden)

Professor David Price (UK)

Professor James Reid (New Zealand)

Dr Miguel Roman (Spain)

Dr Reggie Spelman (Ireland)

Dr Ron Tomlins (Australia)

Professor Thys van der Molen, (IPCRG)

Professor Onno van Schayck

(The Netherlands)

ISSN: $1471-4418$

The General Practice Airways Group (GPIAG) is an independent,

multi-funded, GP-led member

organisation that aims to improve

respiratory care and is a company limited by guarantee (Company No. 4298947).

The peer reviewed Primary Care Respiratory Journal is published by GPIAG Publishing and is the official journal of the GPIAG and International Primary Care Respiratory Group (IPCRG).

All correspondence concerning this journal should be addressed to the Editor.

All editorial decisions are independent of commercial restraints.

The views expressed in this journal are not necessarily those of the GPIAG or IPCRG.

(c) GPIAG. All rights reserved. No part of this publication may be reproduced, stored in a retrieval system or transmitted, in any form or by any means, without the prior permission of the GPIAG. 
The GPIAG wishes to thank Merck Sharp \& Dohme for providing an educational grant to fund the production and distribution of this supplement

\section{General Practice Airways Group Limited}

Chairman: Dr John Haughney, Chief Executive: Mrs Pauline Johnson, Editor: Dr Mark Levy GPIAG Chair in Primary Care Respiratory Medicine: Professor David Price

Trustees:

Dr David Bellamy (chairman), Professor Sean Hilton, Ms Melinda Letts,

Publishers: GPIAG Publishing, 8th Floor, Edgbaston House, 3 Duchess Place, Edgbaston, Birmingham, B16 8NH Tel: +44 (0)121 4548219 Fax: +44 (0)121 4541190 Email: publishing@gpiag.org

Website: http://www.gpiag.org

Registered Offices and Secretariat: GPIAG Publishing, 8th Floor, Edgbaston House, 3 Duchess Place, Edgbaston, Birmingham, B16 8NH

Tel: +44 (0)121 4548219 Fax: +44 (0)121 4541190 Email: info@gpiag.org

Website: http://www.gpiag.org Journal website: http://www.thepcrj.com 